\title{
EUDAIMONIA NO PENSAMENTO OCIDENTAL DO SÉCULO XXI: ALIENAÇÃO POLÍTICA NA ERA PÓS-RACIONAL
}

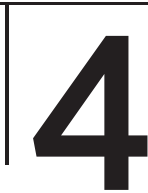

\section{EUDAIMONIA IN 21ST CENTURY WESTERN THINKING: POLITICAL ALIENATION IN THE POST-RATIONAL ERA}

MAGALHÃES, Ana Lucia

Doutora e Mestre em Língua Portuguesa pela PUC-SP e pós-doutora em Retórica pela PUC-SP Coordenadora e professora do Curso Superior de Tecnologia - FATEC-Cruzeiro/SP E.mail: ana.magalhaes01@fatec.sp.gov.br> ORCID ID: https://orcid.org/0000-0003-4146-2677

\section{RESUMO:}

A felicidade é tratada como um conceito baseado na eudaimonia de Aristóteles, com acréscimos de outros filósofos, como Sócrates, Platão, Espinosa e aplicada aos desenvolvimentos políticos atuais. O estudo de caso analisa dois discursos de líderes mundiais: a alemã Angela Merkel em uma entrevista coletiva após uma visita a um campo de refugiados, prometendo a aceitação de um grande número de refugiados, e Donald Trump durante sua campanha eleitoral, propondo um muro contendo imigrantes na fronteira EUA-México. As perguntas da pesquisa são: qual é a relação entre a felicidade aristotélica e a nobreza de caráter? Existem contribuições significativas de outros filósofos? Como o discurso de Merkel sobre aceitação de refugiados aborda a eudaimonia? Como o discurso de Donald Trump no muro da fronteira mexicana se relaciona com a felicidade? Assim, o objetivo da pesquisa é contribuir, através do estudo de conceitos de Aristóteles e outros filósofos, além de trabalhos acadêmicos publicados entre 2016 e 2018, para aprofundar o entendimento da eudaimonia na política do século XXI.

Palavras-chave: Felicidade. Virtude. Vida política. Moral

\section{ABSTRACT}

Happiness is treated as a concept based on Aristotle's eudaimonia with additions by other philosophers, like Socrates, Plato, Spinoza and 
applied to present-day political developments. The case study analyzes two speeches by world leaders: Germany's Angela Merkel at a press conference following a visit to a refugee camp, pledging acceptance of a large number of refugees, and Donald Trump during his electoral campaign, proposing an immigrant-containing wall at the US-Mexico border. The research questions are: what is the relationship between Aristotelian happiness and nobleness of character? Are there significant contributions from other philosophers? How does Merkel's speech on refugee acceptance approach eudaimonia? How does Donald Trump's discourse on the Mexican border wall relate with happiness? So, the research purpose is to contribute, through studying concepts by Aristotle and other philosophers plus academic papers published between 2016 and 2018, to further the understanding of eudaimonia in $21^{\text {st }}$ century politics.

Keywords: Happiness. Virtue. Political life. Moral

\section{INTRODUÇÃO}

Aristóteles, na ética a Nicômaco, associa a felicidade ao fato de que "todo conhecimento e todo trabalho visam algum bem", e tanto o homem comum como o sábio veem esse objetivo como identificar "experimentar o bem viver e a realização de boas ações como ser feliz". A diferença entre os dois é a identificação realista da felicidade com prazeres comuns versus o refinamento da honra, que é o objetivo final da vida política. Torna-se claro que a política é vista aqui como próxima do conceito de virtude, entendida como: 1) virtude intelectual, incluindo sabedoria filosófica, compreensão e conhecimento prático; 2) virtude moral, significando julgamento e temperança. Aristóteles também escreveu que a virtude não nasce com o homem, mas vem com treinamento e exercício.

A felicidade é geralmente buscada em si mesma, como honra, prazer ou razão, o que a torna possivelmente difícil de encontrar, uma vez que é considerada absoluta e autossuficiente, o que significa que o homem feliz é aquele que age com retidão e vive bem, já que a felicidade aristotélica seria uma combinação de boa vida e boas ações. No entanto, também pode ser identificado com virtude, com sabedoria prática ou sabedoria filosófica, combinada ou não com a sensação de prazer. A felicidade é, portanto, "a melhor, a coisa mais nobre e agradável do mundo", e esses atributos da felicidade aparecem juntos, não separadamente. 
Spinoza considerava o homem constrangido por forças externas e influenciado por suas relações com o mundo e com Deus, forçando-o a ser ao mesmo tempo transcendente e mundano. Espinosa olhou para a liberdade e a causa - Deus é a causa ativa, portanto livre e irrestrita, enquanto o homem é restringido por forças externas e, portanto, nunca será livre. Dotado de ação e paixão, ele não pode ser ativo, pois é constituído por forças que vêm de fora. O homem oscila entre paixões: raiva, raiva, medo, esperança, tristeza, alegria. Ao afirmar que "qualquer coisa pode ser acidentalmente causa de esperança ou medo", Spinoza afirma que a esperança é o oposto do medo. Se o medo é "uma tristeza inconstante, surgida da imagem de uma coisa duvidosa", a esperança é "uma alegria inconstante que surge da imagem de uma coisa futura ou passada, de cujo resultado duvidamos". Como a alegria é um produto da paixão, é necessariamente inconstante; portanto, a verdadeira alegria ou felicidade está ligada à racionalidade, longe da paixão: quem vive racionalmente está livre do medo, experimenta apenas a felicidade.

A consideração da felicidade como bem supremo, a busca da virtude através da prática racional de boas ações longe das paixões lembra fatos e situações políticas no Ocidente, como a Declaração de Independência Americana de 1776, que contém a famosa declaração de Thomas Jefferson: "[ ..] os homens [...] são dotados [...] de certos direitos inalienáveis, entre os quais a vida, a liberdade e a busca da felicidade". Sobre o mesmo tema, Bentham escreveu que "a felicidade, ou o prazer, é o bem supremo para a humanidade, e que a maior felicidade do maior número é a base da moral e da legislação".

O discurso de Merkel está claramente relacionado à eudaimonia, pois mostra um forte componente de nobreza; propõe esperança espinosana no futuro;; promove, como Jefferson afirmou, a busca da felicidade e adere a Bentham quando ela propõe abranger o maior número possível de pessoas. Trump desconsidera a eudaimonia aristotélica ao excluir o outro; ele nega a esperança de Espinosa, promovendo tristeza e medo; sua proposta egocêntrica nega a busca da felicidade. Seu discurso vai contra os princípios da Declaração Americana de Independência, que deixa claro que todos os homens foram criados iguais, com os mesmos direitos.

\section{BEM, VERDADE, ÉTICA E FELICIDADE}

Antes de um mergulho analítico sobre discursos atuais, em qualquer área do conhecimento, é sempre necessária uma caminhada, breve 
que seja, pelos gregos. O tema - presença da eudaimonia - constituise particularmente um desafio, considerando que a velocidade trazida pela pós-modernidade, nas palavras de Bauman (2007), deu origem à "realidade líquida", ambiente novo sem precedentes para as atividades individuais, que cria uma série de estímulos inéditos. Em primeiro lugar, porque as organizações sociais não podem mais manter uma mesma forma por muito tempo, levando em conta que se desintegram mais rápido do que a duração para moldá-las, reorganizá-las; em segundo lugar, "a separação e iminente divórcio entre poder e política", que agora se afastam na direção de um espaço global, promovem, ainda segundo o pensador,

uma fonte de profunda e, em princípio, incontrolável incerteza, enquanto a falta de poder torna as instituições políticas existentes, assim como suas iniciativas e seus empreendimentos, cada vez menos relevantes para os problemas existenciais dos cidadãos dos Estados-nações e, por essa razão, atraem cada vez menos a atenção destes.

Ao se aprofundar no mundo de incertezas de Bauman, é possível que a sensação inicial do leitor seja de medo, injustiça, privações, falta de privacidade - promovida pela globalização. É de se perceber ainda que o bem-estar de um espaço está sempre referenciado à miséria de outro. Uma visão pessimista.

No entanto, o homem tem sobrevivido às intempéries, às guerras, a diferentes tipos de mudanças, à violência. Um retorno a Platão e Aristóteles, jamais esgotados ou ultrapassados, mostra que a estrutura fundamental da ética eudaimônica pode ser (ou tem sido) um caminho. Diversos outros pensadores dedicaram a vida na busca de respostas, com algumas pistas próximas, algumas provas, mas não há espaço, neste texto, para todos. Assim, utilizaremos, além dos citados, Espinoza.

\section{SÓCRATES E PLATÃO}

O artigo de Dinucci (2009), Universidade Federal de Sergipe, pretende mostrar a relação entre virtude e felicidade em Sócrates e, para tanto, baseia-se em duas teses: a de Irwin (1995), segundo a qual existiria uma instrumentalidade entre elas e, nesse caso, a virtude seria um meio para atingir a felicidade (2009: 254), e a de Vlastos (1994), para quem a virtude é um componente da felicidade.

Ainda segundo Dinucci, os primeiros diálogos socráticos apoiam teses diferentes sobre tal relação: Protágoras, por exemplo, mostra a 
virtude como instrumento para atingir a felicidade, coisas prazerosas. Em Eutidemo, a sabedoria que torna o homem virtuoso é o único bem e implica na felicidade, conceito reafirmado na Apologia, na República e em Górgias. Além da virtude, Sócrates mostra, na Apologia, a riqueza também como bem e, em Górgias, o filósofo aponta a sabedoria como bem. Em outras palavras, há, para além da virtude, outros elementos que constituem a felicidade humana.

Conforme comentado, Irwin (1995) aponta que a virtude é causa da felicidade, assim, a posição eudaimônica socrática possui três princípios: a) busca a própria felicidade em todas as ações racionais, b) procura a felicidade em si própria e c) qualquer ação racional é procurada em prol da felicidade.

A resposta sobre a constituição da felicidade para Sócrates é respondida por Protágoras, segundo o qual, nas palavras de Irwin, "são consideradas coisas boas porque se supõe que são prazerosas, mas não as consideramos prazerosas porque são boas" (1995, p. 81). Devemos lembrar que Sócrates está sempre comprometido com a virtude e o bem viver, e isso parece ir de encontro a uma tese instrumentalista da felicidade.

Nesse sentido, Vlastos (1994) reforça a tese não instrumentalista das ideias de Sócrates sobre a felicidade, uma vez que defende o "princípio socrático da virtude", anunciado na Apologia:

Homem, tu estás errado se pensas que um homem no qual há mesmo o menor mérito deva considerar o perigo de vida ou morte, e não considerar apenas se, quando ele faz algo, o que ele faz é justo ou injusto, se e o ato de um homem bom ou de um homem mau (Platão, 1995, 28b 5-9) [...] Aqui está a verdade sobre a questão, homens de Atenas; onde quer que um homem pare, pensando que é melhor estar ali [...] é ali [...] que ele deve permanecer, sem considerar a morte nem qualquer outra coisa que seja diante do risco de agir de modo desonroso (Platão, 1995, 28d 6-10).

Há inúmeras outras passagens que enfatizam tal princípio: Górgias diz que as virtudes, quando possuídas por um homem, tornam-no bom e, logo, feliz. Embora, conforme Vlastos (1994), haja alguma inconsistência no pensamento socrático nas obras da juventude de Platão, quanto à relação de identidade entre virtude e felicidade, esse estudioso defende a tese segundo a qual a felicidade, em Sócrates, admite outros componentes além da virtude, apesar de ela manter seu lugar soberano em relação à 
felicidade: "A virtude é necessária e suficiente para a felicidade, porém esta aceita outros componentes de menor importância" (VLASTOS, 1994, p. 298).

Não nos esqueçamos que Sócrates também reafirma, na Apologia, que os bens morais são superiores aos não morais: a perfeição da alma é atingida quando ela se torna virtuosa: "Sócrates: se eu descobrir que ele não possui a virtude, mas a diz possuir, eu o repreenderei por atribuir o menor valor ao que tem o mais alto valor e der o maior valor àquilo que é inferior" (PLATÃO, 1995, 29). Assim como tal passagem da Apologia, em Górgias e na República, Sócrates quando fala sobre a escolha entre sofrer uma injustiça ou cometê-la, responde que não desejaria nenhuma delas, mas se fosse obrigado a escolher, preferiria sofrê-la. Sofrer a injustiça, embora injusto para o sofredor, para Sócrates se torna uma escolha pelo justo e aí também reside a eudaimonia - é feliz o homem virtuoso. Ou seja, a virtude auxilia o homem a suportar a adversidade: aí está a virtude e a felicidade.

Esse conceito de felicidade, naturalmente, não está ligado ao de prazer ou dor, mas ao bem e mal. Lembremos ainda que, para Sócrates, a prática da filosofia, o filosofar habilita o homem à felicidade, ou seja, trata-se de uma relação entre o autoconhecimento, o conhecimento (episteme), a virtude (areté) e a felicidade (eudaimonia).

\section{ARISTÓTELES}

É certo afirmar que a felicidade é a busca de todo homem e, em Aristóteles, muito antes de reduzida à publicidade desde o século XX, era um ideal ético. Enquanto alguns indivíduos possuem uma visão aristotélica de felicidade - a busca do sumo bem - mesmo sem saber, outros a associam a algo simples e óbvio: o prazer, a riqueza, as honras, o poder, mesmo que discordem entre si. Alguns a relacionam à saúde, principalmente se estiverem doentes; outros aos ganhos, mormente se são pobres. Em outras palavras, para esses, a felicidade parece estar sempre além do seu alcance.

O filósofo trata da eudaimonia em seu livro "Ética a Nicômaco" e explica sobre os bens e as vantagens por eles trazidas. Antes, porém, é preciso determinar qual o fim da natureza humana e em que se constitui o bem, o prazer, a virtude, a felicidade - separar, por exemplo, o bem em si mesmo daquilo que é útil. Além disso,

[...] como a palavra "bem" tem tantos sentidos quantos "ser" (visto que é predicada tanto na categoria de substância, como de Deus e da razão, quanto na de qualidade, isto 
é, das virtudes; na de qualidade, isto é, daquilo que é moderado; a de relação, isto é, do útil; na de tempo, isto é, da oportunidade apropriada; na e espaço, isto é, do lugar apropriado etc.) está claro que o bem não pode ser algo único e universalmente presente, pois se assim fosse não poderia ser predicado em todas as categorias, mas somente numa. (ARISTÓTELES, 1975, p. 253)

Como para todas as coisas há um fim, segundo o filósofo, esse fim deve ser o Sumo Bem, ou seja, ele merece ser buscado em si mesmo, embora afirme que talvez esse conceito "pareça uma banalidade" (p. 255) e falte explicar mais claramente o que seja. Nas palavras de Aristóteles, o Sumo Bem seria absoluto e incondicional, aquilo que é desejável em si mesmo e não se relacione a outra coisa "falamos dos bens em dois sentidos: uns devem ser bens em si mesmos, e os outros, em relação aos primeiros" (p. 253).

Dessa forma, a felicidade verdadeira seria procurada em si mesma e nunca com vistas a outra coisa, ao passo que o prazer, por exemplo, estaria relacionado a espécies de homens. Os prazeres estariam em conflito, pois se ligariam ao que cada indivíduo entende como motivo de prazer, alguma espécie de acessório. A felicidade derivada de qualquer espécie de prazer desejado se esgota tão logo esse tenha sido alcançado. Assim, a felicidade em si mesma, aquela não resultante de qualquer desejo passa a ser virtuosa e relacionada à sabedoria filosófica, ou seja, não se esgota. Esse conceito se ajusta ao de virtude, atividade virtuosa.

Aristóteles, ao questionar se a felicidade seria adquirida pela aprendizagem, pelo hábito ou por adestramento, se conferida por providência divina ou ainda pelo acaso, responde que, como virtude, seria o que há de melhor, dessa forma, deveria ser partilhada pelo maior número de pessoas. Nesse ponto, afirma que a felicidade "é o objetivo da vida política" e que "essa ciência dedica o melhor de seus esforços a fazer com que os cidadãos sejam bons e capazes de nobres ações" ( $p$. 259).

Conforme comentado, para melhor entender a natureza da felicidade, o filósofo associa a felicidade à virtude

ao falar do caráter de um homem não dizemos que ele é sábio ou que possui discernimento, mas que é calmo, amável ou temperante; porém louvamos um homem sábio referindo-nos à sua disposição de espírito, e às disposições de espírito louváveis chamamos virtudes (ARISTÓTELES, 1975, p. 263) 
E acrescenta que o homem verdadeiramente político também "goza a reputação de haver estudado a virtude acima de todas as coisas, pois deseja fazer com que os seus concidadãos sejam bons e obedientes às leis" (p. 263).

A virtude a que o filósofo se refere é a humana, pois humano era o bem e humana a felicidade, mas não se trata da virtude do corpo, senão a da alma, uma vez que a felicidade também é a da alma. O político, então, deve saber o que diz respeito à alma, exatamente porque precisa tratar das virtudes, divididas em duas espécies: a intelectual e a moral; a primeira, ligada ao ensino, à experiência, ao tempo e a moral, adquirida pelo hábito, ou seja, a virtude (nenhuma de suas espécies) nasce com o homem, mas é adquirida pela prática.

O filósofo comenta que o homem possui, por natureza, a potência, ou seja, a capacidade de adaptar-se. Cita que os sentidos são inatos (visão, audição...), aparecem antes de serem utilizados, bem ao contrário da virtude, oposta ao que é inato, é adquirida pelo exercício, pelo uso, pelo fazer. E acrescenta que, potencialmente, temos a capacidade da virtude, da justiça e de todos os bens (ou seus contrários), mas somente pelos atos, ações, pelo exercício, nos tornamos verdadeiramente virtuosos.

Às ações ligam-se o agradável e o desagradável, os prazeres e as dores, assim, como é mais fácil aceitar os prazeres, é de se entender que a virtude nem sempre possa ser exercitada por ser difícil. A ciência política, por sua vez, "gira em torno de prazeres e dores, de vez que o homem que lhes der bom uso será bom e o que lhe lhes der mau uso será mau". (ARISTÓTELES 1975, p. 270).

Aristóteles reforça que a virtude está associada à alma, porém, embora ela possua "três espécies de coisas" (1975, p. 271) - paixões, faculdades e disposições de caráter - a virtude só pode estar relacionada à terceira, pois ninguém é louvado ou censurado pelas paixões em geral (cólera, medo, inveja, alegria, ódio, emulação, compaixão), mas por algumas delas; nem pelas faculdades.

Quando se fala em paixões, percebem-se dois extremos e o estagirita comenta sobre falta, excesso e meio-termo, ou seja, relaciona o meio-termo ao "equidistante de ambos os extremos" (1975, p. 272). Para ele, falta e excesso estão longe da virtude e esta seria

mais exata e melhor que qualquer arte, como também o é a natureza, segue-se visar ao meio-termo. Refiro-me à virtude moral, pois é ela que diz respeito às paixões e ações, nas quais existe excesso, carência e meio-termo. Tanto o medo como a confiança, o apetite, a ira, a compaixão e em geral 
prazer e a dor, podem ser sentidos em excesso ou em grau insuficiente; e num caso como noutro, isso é um mal. Mas senti-los na ocasião apropriada, com referência aos objetos apropriados [...] nisso consistem o meio-termo e a excelência característicos da virtude.

Tendo em vista que Aristóteles associa a virtude à felicidade e essa deve ser adquirida pelo homem, é de se pensar que o exercício do meio-termo seja uma forma de conquista da felicidade, o que não seria exatamente tarefa fácil e estaria mais próximo do filósofo, acostumado à busca da contemplação da verdade: somente onde há contemplação é que se chega à felicidade e, "nesse sentido o filósofo é o mais feliz dos homens" (p. 367).

\section{ESPINOSA}

A intenção neste trabalho é mostrar apenas algumas luzes que Espinosa lança sobre a felicidade, para isso, a pesquisa limitou-se ao Tratado da Correção do Intelecto que, em seu primeiro parágrafo, diz:

Desde que a experiência me ensinou ser vão e fútil tudo o que costuma acontecer na vida cotidiana, e tendo eu visto que todas as coisas de que me arreceava ou que temia não continham em si nada de bom nem de mau senão enquanto o ânimo se deixava abalar por elas, resolvi, enfim, indagar se existia algo que fosse o bem verdadeiro e capaz de comunicar-se, e pelo qual unicamente, rejeitado tudo o mais, o ânimo fosse afetado; mais ainda, se existia algo que, achado e adquirido, me desse para sempre o gozo de uma alegria contínua e suprema (ESPINOSA, 1980).

O texto deixa claro o interesse ético e uma preocupação pela busca do bem supremo, associado a uma necessidade fundamental de procura pela felicidade e está associado ao seu projeto filosófico, inteiramente orientado pela busca do bem supremo definido como "o conhecimento da união que a mente tem com toda a Natureza".

O filósofo que procurou pensar o homem e suas relações com o mundo e com Deus (entendido no mesmo nível da natureza, ou seja, os dois são o mesmo), preocupou-se com o problema da Liberdade - Deus está ligado à ideia de liberdade. Por outro lado, o homem é dotado de ação e paixão, dessa forma, não é livre, ou seja, oscila em suas paixões: cólera, medo, esperança (ESPINOSA, 1980, p. 159). Ao afirmar que "qualquer coisa pode ser, por acidente, causa de esperança 
e medo (1980, p. 159), coloca o medo como "uma tristeza inconstante, surgida da imagem de uma coisa duvidosa", enquanto a esperança é "uma alegria inconstante, surgida da imagem de uma coisa futura ou pretérita, de cuja realização duvidamos" (1980, p. 139).

Para o pensador, o conhecimento promove a integração do homem e gera "alegria contínua e suprema", ou seja, conhecimento e felicidade estariam ligados. Enquanto os homens em geral buscam riquezas, honras e prazeres, Espinosa indagou se haveria algo que desse origem à felicidade suprema ou ela seria a junção desses três bens: pela riqueza, honra e prazer "a mente se vê tão distraída que de modo algum poderá pensar em qualquer outro bem" (§ 3). E reforça o que pensa a respeito das três formas que se constituem como sentido da vida para grande parte dos indivíduos: 1) o prazer buscado por si mesmo causa tristeza profunda após a fruição, pois o espírito fica por ele embotado, impossibilitado de pensar em outro assunto; 2) as riquezas perseguidas por si mesmas absorvem o homem e direcionam todas as suas ações. Quanto mais conseguem, mais desejam e se não a obtém, ele é atingido por tristeza, frustração e abatimento; 3) as honras, por sua vez, causam males na medida em que os indivíduos precisam se sujeitar a outros.

Espinosa (1980) escreveu que

As coisas perseguidas pelo vulgo não contribuem em nada para a conservação do nosso ser, mas ao contrário, são nocivas. [...] E não menor é o número daqueles que, para alcançar ou defender honra, acabam miseravelmente [...] o amor por aquilo que é eterno e infinito enche o espírito de pura alegria, inteiramente privada de tristeza, o que constitui um bem a desejar e buscar com todas as nossas forças.

Em outras palavras, o perecível nos afeta com tristeza, uma vez que a felicidade será passageira. Por outro lado, a busca pelo eterno nos traz a real felicidade. Enquanto os prazeres, riquezas e honras em si mesmos são passageiros e causam males, podem ser motivo de felicidade se colocados como instrumentos na procura pelo bem supremo, que se encontra na adequação entre corpo, mente e natureza, ou seja "todas as nossas ações e pensamentos devem ser dirigidos a esse fim".

\section{A POLÍTICA E A EUDAIMONIA}

Para uma análise do que nos falam Sócrates, Platão, Aristóteles e Espinoza sobre eudaimonia, escolhemos trechos de discursos proferidos 
por dois dirigentes de países importantes que, sobre temas semelhantes, mostram escolhas diferentes: a Chanceler Angela Merkel, em discurso proferido em 2018, em Marrakesh, explica sobre a adoção do pacto global para migração segura e o presidente Trump, em um discurso de campanha, em Phoenix, Arizona (2016), argumenta sobre a construção de um muro entre o México e os EUA, e. Os textos estão reproduzidos ao final do artigo, mas serão tomados apenas alguns trechos, uma vez que os discursos são muito longos. A intenção é mostrar se e de que maneira a eudaimonia está associada, nesses discursos, ao que pregam os filósofos estudados.

O discurso da chanceler tem início após a saudação inicial às autoridades, com a descrição do estado de espírito da oradora. (tradução da autora - ver texto original nas notas i a v)

Estou muito feliz por estar aqui com vocês em Marrakech hoje. Gostaria de expressar os meus sinceros agradecimentos aos nossos anfitriões marroquinos, bem como às Nações Unidas e a todos os outros que tornaram esta conferência possível.

Hoje é um dia muito importante. Estamos adotando um acordo político abrangente sobre migração a nível global pela primeira vez. A Assembleia Geral das Nações Unidas estava certa em se concentrar em duas questões em 2016 - por um lado, o tema dos refugiados, cuja base jurídica é a Convenção sobre o Estatuto dos Refugiados, e, por outro lado, o tema da migração, uma questão que afeta milhões de pessoas em todo o mundo. Uma clara distinção foi feita aqui entre refugiados e migração, o que é particularmente significativo. É por isso que dois Pactos Globais foram elaborados como resultado. E ambos devem ser adotados pela Assembleia Geral antes do final de dezembro.

A disposição em que os argumentos são postos no texto mostram as intenções persuasivas, que ocorrem por meio das unidades temáticas. Perelman (1993: 151), ao refletir sobre a força dos argumentos e sua relação com a ordem em que aparecem, enumera a crescente, a decrescente e a nestoriana (meio termo entre as ordens).

Como verificamos, a oradora emprega a decrescente, uma vez que inicia com seu estado de espírito: "estou muito feliz", um argumento forte, seguido da nestoriana. O meio termo, aliás, está relacionado à 
virtude, conforme concebida por Aristóteles, e essa, à felicidade. Não se trata da felicidade comentada em Protágoras, que mostra a virtude como instrumento para atingir a felicidade, coisas prazerosas, mas um sentimento relacionado ao outro: "Estamos adotando um acordo político abrangente sobre migração a nível global pela primeira vez [...] o tema dos refugiados, cuja base jurídica é a Convenção sobre o Estatuto dos Refugiados, e [...] o tema da migração, uma questão que afeta milhões de pessoas em todo o mundo." Uma preocupação mundial, com o bem do outro.

O sentimento de felicidade explicitado no início do texto prepara o auditório e é construído nos parágrafos seguintes

[...] é particularmente apropriado que também consideremos o destino dos muitos milhões de migrantes em todo o mundo e reiteramos nossa convicção de que a humanidade universal os direitos se aplicam a todos os indivíduos em todos os países da terra. [...] hoje estamos a adoptar este Pacto, que afirma expressamente que o seu foco é uma migração segura, ordenada e regular. [...] Ficou claro, e também faz sentido que esse objetivo só possa ser alcançado por meio da cooperação multilateral. Poderíamos, portanto, dizer que, 70 anos após a adoção da Declaração Internacional dos Direitos Humanos, é hora de voltarmos nossa atenção conjunta para a questão da migração. A migração é uma ocorrência natural e frequente, e é uma coisa boa quando ocorre legalmente

A preocupação com o bem universal, com a aplicação dos direitos a todos os indivíduos da terra retira do texto possíveis apreensões consigo: mostra um ethos voltado ao bem comum: a oradora fala que a migração "é uma coisa boa quando ocorre legalmente". Lembramos Aristóteles segundo quem o homem verdadeiramente político também "goza a reputação de haver estudado a virtude acima de todas as coisas, pois deseja fazer com que os seus concidadãos sejam bons e obedientes às leis".

O termo terra associado a todos os indivíduos tem força retórica, pois não se trata de um termo gasto em discursos (globalização, por exemplo), mas de uma escolha lexical cuidadosa. É de se pensar no Sumo Bem comentado por Aristóteles e no conceito de liberdade, de Espinosa, quando o discurso apregoa sobre a Alemanha, que "é um membro da União Europeia. [...] gozamos de liberdade de movimento 
para o emprego. Esse é um aspecto do nosso mercado único, e isso traznos uma maior prosperidade". A liberdade espinosana está relacionada à ideia do bem supremo. Enquanto o homem for um ser dominado por paixões, não será livre.

No entanto, o texto não deixa de tangenciar o utilitário e nos lembramos de Sócrates, para quem, além da virtude, do bem supremo, outros elementos podem constituir a felicidade humana: na Apologia, a riqueza e, em Górgias, a sabedoria.

É por isso que a migração laboral na União Europeia é claramente regulamentada, refletindo também os princípios deste pacto. Devido ao seu desenvolvimento demográfico, a Alemanha é um país que no futuro continuará a exigir um maior número de especialistas qualificados, incluindo mais especialistas de países fora da União Europeia. Portanto, temos interesse na migração legal. E o que é do nosso interesse também está sujeito ao nosso direito soberano à autodeterminação. O Pacto Global afirma especificamente que os Estados-Membros têm o direito soberano de determinar as suas próprias políticas (grifos nossos)

O texto de Angela mostra que há um interesse do país na migração. Nesse caso, deixamos de pensar a eudaimonia socrática, platônica, aristotélica ou espinosana como bem supremo, ligada ao caráter, uma questão ética, moral e de valores, mas voltamos àquele conceito de felicidade comentado por esses pensadores em relação aos homens comuns: prazer, honra, riqueza.

No entanto, estamos conscientes de que, mesmo no contexto da migração legal como existe no mundo de hoje, algumas pessoas estão expostas a condições de trabalho extremamente injustas. O trabalho infantil ainda é uma realidade. Condições de trabalho difíceis são uma realidade. [...] destinado a prevenir e combater a migração ilegal, [...] o tráfico humano. [...] todo indivíduo deve ter documentação adequada. Estamos todos conscientes dos riscos que as pessoas que caem nas mãos de traficantes de seres humanos e contrabandistas estão expostos.

O texto da chanceler continua a demonstrar um chamamento ao caráter, à busca pela justiça, aos direitos dos indivíduos e a apelar contra as más condições de trabalho, à ilegalidade que conduz ao tráfico 
humano, e aos riscos que os homens correm nas mãos de indivíduos desprovidos de caráter.

É por isso que vale a pena lutar por este Pacto - tanto por causa das muitas pessoas que assim poderão ter uma vida melhor, como por seu compromisso claro com o multilateralismo. Esta é a única maneira de podermos tornar nosso mundo um lugar melhor. A Alemanha está comprometida com essa tarefa. [...] A Alemanha continuará a desempenhar um papel ativo na sua posterior implementação para o benefício das pessoas do nosso planeta

Finaliza o discurso com um apelo a que todos se comprometam no sentido de melhorar o mundo para que as pessoas se beneficiem. Descontando o momento em que o pronunciamento cita o interesse da Alemanha pelos trabalhadores - aspecto utilitário do texto - podese dizer que todo o discurso se pauta pelos conceitos de eudaimonia conforme Sócrates e Espinosa, uma vez que procura o bem geral do indivíduo e associados à virtude, mostrada por Aristóteles como caminho do meio, a não ser apenas o trecho que fala do interesse da Alemanha na mão de obra estrangeira.

O discurso do presidente Trump, proferido em 31 de agosto de 2016, tem início com agradecimentos ao povo e com a descrição de seu estado de espírito: encontra-se feliz por estar em Phoenix. Utiliza da repetição no começo (quatro agradecimentos em quatro frases) e ao longo de todo o texto, como reforço aos argumentos escolhidos. (tradução da autora - ver texto original nas notas vi a ix).

Uau. Obrigado. É muita gente, Phoenix, é muita gente. Muito obrigado. Obrigado, Phoenix. Estou tão feliz por estar de volta ao Arizona. O estado que tem um lugar muito, muito especial no meu coração. Eu amo as pessoas do Arizona e juntos chegaremos à Casa Branca em novembro. Agora, você sabe que é aqui que tudo começou para mim. Lembram também daquela enorme multidão? Então, eu disse: vamos nos divertir hoje à noite. Nós estamos indo para o Arizona, OK? Isso será um pouco diferente. Este não será em si um discurso de comício.. Em vez disso, vou apresentar em detalhe um dos maiores desafios que o país enfrenta atualmente, a imigração ilegal. Acabei de 
chegar de uma reunião muito importante e especial com o presidente do México, um homem de quem eu gosto e a quem respeito muito. $\mathrm{E}$ um homem que realmente ama seu país, o México, assim como eu aliás sou um homem que ama meu país, os Estados Unidos. [...] E em um governo Trump, vamos criar um novo relacionamento entre nossos dois países, mas será um relacionamento justo. Queremos justiça. Mas, para consertar nosso sistema de imigração, precisamos mudar nossa liderança em Washington e devemos mudá-la rapidamente. Infelizmente, infelizmente não há outro caminho. A verdade é que nosso sistema de imigração é pior do que o que alguém jamais imaginou.

Percebe-se, de imediato, que Trump tem sua felicidade direcionada a um desejo quase pessoal: "juntos chegaremos à Casa Branca em novembro". Logo em seguida, coloca o item em torno do qual girará seu discurso: anuncia uma política sobre a imigração. A chanceler se preocupa com o bem-estar dos imigrantes e o presidente anuncia uma política sobre a imigração. É interessante que ele apresenta o presidente do México como um homem que ama seu país e apresenta a si como um homem que ama seu próprio país: de alguma forma, já se apresenta uma política separatista: cada qual em seu espaço próprio. Reforça que os dois estão em conversação e ambos os países ganharão com a política a ser anunciada - enfatiza que será criada uma nova relação entre aqueles dois países e, com a adversativa "mas", apresenta que será uma relação justa. É possível pensar na justiça aristotélica, socrática, platônica, que só poderá ser verificada ao longo do texto.

Outra adversativa mostra que a justiça vai depender da colocação de pessoas em postos-chave: "Mas, para consertar nosso sistema de imigração, precisamos mudar nossa liderança em Washington e devemos mudá-la rapidamente. Infelizmente, infelizmente não há outro caminho". A escolha lexical pelo advérbio "infelizmente" (sadly), repetido duas vezes, deixa perceber que não será uma transição fácil e, segundo o presidente, não há outra alternativa. Na sequência, o texto informa que: "A verdade é que nosso sistema de imigração é pior do que o que alguém jamais imaginou.." e, com tal afirmação, reforça que o anúncio e as decisões que virão podem não ser aceitos, porém são absolutamente necessários: 
Hoje, em um assunto muito complicado e muito difícil, vocês vão saber a verdade. O problema fundamental do sistema de imigração em nosso país é que ele atende às necessidades de doadores ricos, ativistas políticos e políticos muito, muito poderosos. [...] Não serve para vocês, o povo americano. Quando os políticos falam sobre a reforma da imigração, geralmente querem dizer o seguinte: anistia, fronteiras abertas, salários mais baixos. A reforma da imigração deve significar algo totalmente diferente. Deve significar melhorias em nossas leis e políticas para melhorar a vida dos cidadãos americanos. [...] Mas se vamos fazer o nosso sistema de imigração funcionar, temos que estar preparados para conversar honestamente e sem medo sobre essas questões importantes e muito sensíveis. Essas são preocupações válidas, expressas por cidadãos decentes e patrióticos de todas as origens, em todos os lugares [...] Incontáveis vidas americanas inocentes foram roubadas porque nossos políticos falharam em seu dever de proteger nossas fronteiras e fazer cumprir nossas leis como elas precisam ser cumpridas.

O discurso mostra como verdade uma visão da época, que reforça não servir ao povo americano. Coloca, dessa forma, um argumento forte que conclama o povo americano a dividir-se para o bem de si próprio "deve significar algo totalmente diferente. Deve significar melhorias em nossas leis e políticas para melhorar a vida dos cidadãos americanos". E reforça "Essas são preocupações válidas, expressas por cidadãos decentes e patrióticos de todas as origens, em todos os lugares.".

O que se percebe até o momento é que existe uma preocupação com o país, não global, mas determinada a uma fatia da população, dessa forma, não se poderia associar a felicidade à eudaimonia socrático platônica (bem supremo), aristotélica (virtude) ou a espinosana.

Ao afirmar que "Mas se vamos fazer o nosso sistema de imigração funcionar, temos que estar preparados para conversar honestamente e sem medo sobre essas questões importantes e muito sensíveis", deixa transparecer a possibilidade de haver desonestidade e medo anteriormente. Reforça que "Incontáveis vidas americanas inocentes foram roubadas porque nossos políticos falharam em seu dever de proteger nossas fronteiras e fazer cumprir nossas leis como elas precisam 
ser cumpridas." Aqui o orador demonstra preocupação em preservar somente o bem-estar de seus concidadãos, sem pensar no bem universal. Trump demonstra um conceito instrumental de felicidade (Irwin, 1995) voltado ao bem pessoal e com um fim específico: preservação do seu país.

Outros argumentos ao longo do discurso reforçam esse conceito: comenta sobre um jovem de 21 anos que foi morto por um imigrante ilegal, membro de gangue. Outra vítima teria sido morta a tiros em uma cidade santuário e uma senhora de 90 anos, espancada em sua residência. Na Califórnia uma veterana da Força Aérea fora estuprada e morta a marteladas e o assassino havia sido preso várias vezes e nunca deportado. Trump cita um relatório de 2011 para afirmar que imigrantes ilegais teriam cometido 25.000 homicídios, parte deles encarcerada a um custo para os EUA, dinheiro que poderia ser gasto em bolsas de estudo para alunos carentes, por exemplo.

Com essas informações, o candidato fortalece a necessidade de impedir a imigração que, segundo ele, é a grande responsável pelos crimes citados. No seu entender, o povo mexicano consiste, em parte substancial, de criminosos, embora não o diga literalmente. O orador conduz o auditório a crer na necessidade de construção de um muro físico entre os países para impedir a imigração e conter a criminalidade.

Construiremos uma grande muralha ao longo da fronteira sul. PLATEIA: Construa o muro! Construa o muro! Construa o muro! E o México pagará pelo muro. Cem por cento. Eles ainda não sabem, mas vão pagar por isso. E eles são ótimas pessoas e grandes líderes, mas vão pagar pelo muro. No primeiro dia, começaremos a trabalhar em um belo muro na fronteira sul, impenetrável, massivo, alto, poderoso. Usaremos a melhor tecnologia, incluindo sensores acima e abaixo do solo, nos túneis. Lembrem-se disso, acima e abaixo. Sensores acima e abaixo do solo. Torres, vigilância aérea e mão-de-obra para complementar o muro, encontrar e deslocar túneis e afastar cartéis criminosos e o México, você sabe disso, trabalhará conosco. Eu realmente acredito nisso. O México trabalhará conosco. Eu absolutamente acredito nisso. E, especialmente, depois de se encontrar hoje com o maravilhoso, maravilhoso presidente deles. $\mathrm{Eu}$ realmente acredito que eles querem resolver esse problema conosco, e tenho certeza que sim. Número dois, 
vamos acabar com essa história de prender e soltar. Nós os pegamos, vamos em frente. Nós os pegamos, vamos em frente. Sob minha administração, qualquer pessoa que atravesse ilegalmente a fronteira será detida até que seja removida do nosso país e retornada ao país de onde veio.

O orador informa, não apenas sobre a construção do muro, apoiado entusiasticamente pelo auditório, mas diz que o México pagará integralmente pela construção desse meio de separação. Nesse ponto fica clara a política isolacionista, que se distancia do que dizem Aristóteles, Platão e Espinosa. Lembremos que Aristóteles nos fala que a felicidade está associada à virtude, meio termo entre os extremos (falta e excesso). A posição de Trump é a do excesso: em princípio, todos os mexicanos que desejam ir para os EUA seriam criminosos em potencial, daí a necessidade da construção de um muro. "Sob minha administração, qualquer pessoa que atravesse ilegalmente a fronteira será detida até que seja removida do nosso país e retornada ao país de onde veio.." O termo usado "removido" está associado a exclusão: pessoas tratadas como objetos indesejados.

Mas a polícia e os agentes da lei sabem quem são essas pessoas. Eles moram com essas pessoas. Eles são ridicularizados por essas pessoas. Eles não podem fazer nada a respeito dessas pessoas e eles querem fazer. Eles sabem quem são essas pessoas. No primeiro dia, minha primeira hora no cargo, essas pessoas irão embora. E você pode chamá-los deportados, se quiser. A imprensa não gosta desse termo. Você pode chamá-lo como quiser. Eles irão embora. [...] eles irão embora. rápido. Emitiremos documentos de detenção para imigrantes ilegais que forem presos por qualquer crime, e eles serão colocados em remoção imediata.

Ao dizer que os policiais sabem quem essas pessoas são, continua a colocar todos os imigrantes como criminosos "qualquer pessoa que atravesse ilegalmente a fronteira". Salienta que os policiais, por exemplo, são achincalhados pelos imigrantes ilegais, sem fazer diferença entre criminosos e pessoas que querem trabalhar naquele país para melhorar de vida, com suas famílias, por exemplo. Afirma que vai expulsar a todos imediatamente. Tal afirmação vai contra o conceito de felicidade visto 
na subseção 1, quando se pensa no bem comum, no supremo bem, na virtude, na felicidade como ligação entre os homens.

É possível que o candidato esteja pensando na conquista de honras para si mesmo: a presidência, mas, para Espinosa, essas são felicidades passageiras e causam males, a não ser quando colocadas como instrumentos na procura pelo bem supremo, o que não parece ser o caso. Há clara busca de bem específico apenas para uma parcela da humanidade.

\section{CONCLUSÃO}

Conforme comentado, ao comparar os tipos de felicidade, percebemos, de imediato, que Angela Merkel pensa de uma forma global, enquanto Trump direciona sua felicidade a um desejo quase pessoal: juntos chegaremos à Casa Branca em novembro" e, em todo o discurso, na felicidade e bem-estar do povo de seu país. A chanceler se preocupa com o bem-estar de todos os imigrantes, lembrando que são pessoas, e o presidente anuncia uma política de expulsão dos imigrantes de seu país. Ela os trata como pessoas, como mão de obra que poderá ajudar a Alemanha e como forma daquele país resgatar-se dos males provocados durante a guerra. O candidato Trump trata-os como criminosos, em princípio, que precisam ser removidos.

Enquanto ela pretende acolhê-los, ele tenciona apartá-los. O termo utilizado pela primeira associa-se a uma procura pelo bem universal, enquanto o segundo aproxima-se de uma visão do imigrante como coisa. Assim, é possível ver, no primeiro discurso, uma associação à virtude aristotélica, à procura do sumo bem socrático, e à liberdade espinosana; no segundo, percebe-se uma visão instrumental. A felicidade existe enquanto conduz a determinado fim.

\section{REFERÊNCIAS}

ARISTÓTELES, Arte Retórica. Lisboa: Imprensa Nacional Casa da Moeda (INCM), 1998. Ética a Nicômaco, In: Os Pensadores. São Paulo: Editora Abril, 1973.

BAUMAN, Zygmund. Tempos Líquidos, Rio de Janeiro: Zahar Editores. 2007.

ESPINOSA, B. Tratado da Correção do Intelecto. São Paulo: Martins Fontes, 2004

ESPINOSA, B. Ética. In: Os Pensadores. São Paulo: Editora Abril, 1975

IRWIN, T. Plato's Ethics. New York: Garland, 536 p., 1995.

PLATÃO, Górgias, Tradução de Daniel R. N. Lopes. São Paulo: Perspectiva, $1^{a}$ edição, 2014. 
PLATÃO, Apologia de Sócrates, Tradução de Maria Lacerda de Moura. Rio de Janeiro: Edições de Ouro, sem data.

PLATÃO. Laches. Protagoras. Meno. Euthydemmus. Londres Harvard University Press, $7^{\mathrm{a}}$ edição, 1990.

PLATÃO. Rebublic (books 1-5), Londres, Harvard University Press, 535 p. $11^{a}$ edição, 1999.

The Federal Government of Germany. Speech by Federal Chancellor Dr Angela Merkel at the Intergovernmental Conference to Adopt the Global Compact for Safe, Orderly and Regular Migration in Marrakech on 10 December 2018. https://www.un.org/en/ conf/migration/assets/pdf/GCM-Statements/germany.pdf, Acesso em: Jun. 2019.

The New York Times. Transcripton of Donald Trump’s Immigration Speech, Sept. 1, 2016. https://www.nytimes.com/2016/09/02/us/politics/transcript-trump-immigrationspeech.html, Acesso em: Jun. 2019.

VLASTOS, G. Socrate: Ironie et Philosophie Morale. Paris, Aubier, 357 p., 1994.

\section{Endnotes}

$<$ ? $\quad$ I am delighted to be here with you in Marrakech today. I would like to express my sincere thanks to our Moroccan hosts, as well as to the United Nations and to everyone else who has made this conference possible. Today is a very important day. For we are adopting a comprehensive political agreement on migration at global level for the first time. The United Nations General Assembly was right to focus on two issues in 2016 - on the one hand the topic of refugees, the legal basis of which is the Convention relating to the Status of Refugees, and on the other hand the topic of migration, an issue affecting millions of people throughout our world. A clear distinction has been made here between refugees and migration, which is particularly significant. That is why two Compacts have been drawn up as a result. And both are to be adopted by the General Assembly before the end of December.

$<$ ? $\quad[\ldots]$ it is particularly appropriate that we are also considering the fate of the many millions of migrants across the globe and reiterating our conviction that universal human rights apply to every individual in every country of the earth.

Ladies and gentlemen, today we are adopting this Compact, which expressly states that its focus is on safe, orderly and regular migration. The very title of the Compact therefore describes its goal very specifically. It has become clear, and it also makes sense that this goal can only be achieved through multilateral cooperation. We could therefore say that 70 years after adoption of the International Bill of Human Rights it is high time that we also turned our joint attention to the issue of migration. Migration is a natural and frequent occurrence, and it is a good thing when it takes place legally 
$<$ ? $>\quad$ That is why labour migration within the European Union is clearly regulated, also reflecting the principles of this Compact. It is all about equal pay for the same work. It is about reasonable standards. All this is something we take for granted within the European Union.

Due to its demographic development, Germany is a country that in future will continue to require higher numbers of qualified experts, including more experts from countries outside the European Union. We therefore have an interest in legal migration. And what is in our interests is also subject to our sovereign right to self-determination. The Compact states specifically that the Member States have the sovereign right to determine their own policies

$<$ ? $\quad \quad$ Nonetheless, we are aware that even within the context of legal migration as it exists in the world today, some people are exposed to extremely unfair working conditions. Child labour is still a reality. [...] intended to prevent and counter illegal migration. [...] human trafficking [...] every individual should have adequate documentation. [...] We are all aware of the risks to which people who fall into the hands of human traffickers and smugglers are exposed

$<$ ? $\quad \quad$ That is why it is worth fighting for this Compact - both because of the many people who will thereby be able to have a better life, and because of its clear commitment to multilateralism. This is the only way that we will be able to make our world a better place. Germany is committed to this task. [...]. Germany will continue to play an active role in its further implementation for the benefit of the people on our planet.

$<$ ? $\quad$ Wow. Thank you. That's a lot of people, Phoenix, that's a lot of people. Thank you very much. Thank you, Phoenix. I am so glad to be back in Arizona. The state that has a very, very special place in my heart. I love people of Arizona and together we are going to win the White House in November. Now, you know this is where it all began for me. Remember that massive crowd also? So, I said let's go and have some fun tonight. We're going to Arizona, O.K.? This will be a little bit different. This won't be a rally speech, per se. Instead, I'm going to deliver a detailed policy address on one of the greatest challenges facing our country today, illegal immigration. I've just landed having returned from a very important and special meeting with the president of Mexico, a man I like and respect very much. And a man who truly loves his country, Mexico. And, by the way, just like I am a man who loves my country, the United States. [...] And in a Trump administration we're going to go about creating a new relationship between our two countries, but it's going to be a fair relationship. We want fairness. But to fix our immigration system, we must change our leadership in Washington, and we must change it quickly. Sadly, sadly there is no other way. The truth is our immigration system is worse than anybody ever realized.

$<$ ? $>\quad$ Today, on a very complicated and very difficult subject, you will get the truth. The fundamental problem with the immigration system in our country is that it serves the 
needs of wealthy donors, political activists and powerful, powerful politicians. [...] It does not serve you the American people. When politicians talk about immigration reform, they usually mean the following: amnesty, open borders, lower wages. Immigration reform should mean something else entirely. It should mean improvements to our laws and policies to make life better for American citizens. [...] These are valid concerns expressed by decent and patriotic citizens from all backgrounds, all over.[...] Countless innocent American lives have been stolen because our politicians have failed in their duty to secure our borders and enforce our laws like they have to be enforced.

$<$ ? $\quad$ We will build a great wall along the southern border. AUDIENCE: Build the wall! Build the wall! Build the wall! And Mexico will pay for the wall. One hundred percent. They don't know it yet, but they're going to pay for it. And they're great people and great leaders but they're going to pay for the wall. On day one, we will begin working on an impenetrable, physical, tall, power, beautiful southern border wall. We will use the best technology, including above and below ground sensors that's the tunnels. Remember that, above and below. Above and below ground sensors. Towers, aerial surveillance and manpower to supplement the wall, find and dislocate tunnels and keep out criminal cartels and Mexico you know that, will work with us. I really believe it. Mexico will work with us. I absolutely believe it. And especially after meeting with their wonderful, wonderful president today. I really believe they want to solve this problem along with us, and I'm sure they will. Number two, we are going to end catch and release. We catch them, oh go ahead. We catch them, go ahead. Under my administration, anyone who illegally crosses the border will be detained until they are removed out of our country and back to the country from which they came.

$<$ ? $\quad$ But the police and law enforcement, they know who these people are. They live with these people. They get mocked by these people. They can't do anything about these people, and they want to. They know who these people are. Day one, my first hour in office, those people are gone. And you can call it deported if you want. The press doesn't like that term. You can call it whatever the hell you want. They're gone. [...] They're going to be gone. They're going out. They're going out fast. We will issue detainers for illegal immigrants who are arrested for any crime whatsoever, and they will be placed into immediate removal.

Recebido em: 08/12/2019

Aceite em: 20/12/2019 